\title{
Therapeutic effects of combined meloxicam and glucosamine sulfate treatment on patients with osteoarthritis, and its effect on serum CTX- I , CTX-II, COMP and MMP-3
}

\author{
Lu Zhijun ${ }^{1}$, Chen Rongchun ${ }^{1}$, Lin Feixiang ${ }^{1}$, Wu Yaohong ${ }^{1}$, Liu Ning', Zhang \\ Shufang ${ }^{1}$, Zhong Mingliang ${ }^{1}$, Zhong Hongfa ${ }^{2}$ \\ ${ }^{1}$ Department of Spinal Surgery, ${ }^{2}$ Department of Trauma, People's Hospital of Ganzhou City, Jiangxi Province, China \\ ${ }^{*}$ For correspondence: Email: ft1192@163.com
}

Sent for review: 8 November 2018

Revised accepted: 16 June 2019

\begin{abstract}
Purpose: To study the therapeutic influence of meloxicam-glucosamine sulfate combination in patients with osteoarthritis and their effect on serum CTX-I, CTX-II, COMP and MMP-3.

Methods: A total of 88 patients with osteoarthritis were assigned to control $(n=44)$ and treatment groups ( $n=44)$, using the random number table method. Control group was given $7.5 \mathrm{mg}$ of meloxicam, while treatment group received $0.5 \mathrm{~g}$ of glucosamine sulfate capsule in addition to meloxicam. Both groups were treated continuously for 8 weeks. Serum levels of C-terminal telopeptide of type I collagen (CTX-I), C-terminal telopeptide of type II collagen (CTX-II), cartilage oligomeric matrix protein (COMP) and matrix metalloproteinase-3 (MMP-3) were compared for the two groups after treatment.

Results: Lysholm score significantly increased in the two groups after treatment. Serum CTX-I, CTX-II, COMP and MMP-3 in the two groups were significantly lower than before treatment, but the reductions were more pronounced in the treatment group $(p<0.05)$. During treatment, mild vomiting and pruritus of the skin appeared in both groups, but these were relieved after symptomatic treatment without any serious adverse reactions.

Conclusion: Treatment with a combination of meloxicam and glucosamine sulfate produces significant beneficial effects in patients with osteoarthritis by reduction of clinical symptoms, pain relief and reduction of serum CTX-I, CTX-II, MMP-3 and COMP.
\end{abstract}

Keywords: Meloxicam, Glucosamine sulfate, Osteoarthritis, MMP-3, CTX-I, COMP, CTX-II

\begin{abstract}
This is an Open Access article that uses a fund-ing model which does not charge readers or their institutions for access and distributed under the terms of the Creative Commons Attribution License (http://creativecommons.org/licenses/by/4.0) and the Budapest Open Access Initiative (http://www.budapestopenaccessinitiative.org/read), which permit unrestricted use, distribution, and reproduction in any medium, provided the original work is properly credited.

Tropical Journal of Pharmaceutical Research is indexed by Science Citation Index (SciSearch), Scopus, International Pharmaceutical Abstract, Chemical Abstracts, Embase, Index Copernicus, EBSCO, African Index Medicus, JournalSeek, Journal Citation Reports/Science Edition, Directory of Open Access Journals (DOAJ), African Journal Online, Bioline International, Open-J-Gate and Pharmacy Abstracts
\end{abstract}

\section{INTRODUCTION}

Osteoarthritis is a disease characterized by degeneration of the joints. It usually occurs in middle-aged people and elderly people aged over 50 years old. The disease manifests in swelling, pain, stiffness, and even limited movement of the joints, all of which greatly affect quality of life of the patients [1]. An important component of articular cartilage is glucosamine sulfate which has special affinity for joints [2]. 
It has been found that glucosamine sulfate relieves the clinical symptoms of osteoarthritis, significantly slows down the progress of disease, and can be taken safely for a long time. Glucosamine sulfate is also important for the repair and improvement of degenerated cartilage, and it is effective in the etiological treatment of osteoarthritis [3].

Meloxicam is a non-steroidal enol antiinflammatory drug with anti-inflammatory, analgesic and antipyretic effects. It is a selective inhibitor of cyclooxygenase-2 (COX-2). It has a weak inhibitory effect on cyclooxygenase-1 (COX-1), and so it has less adverse reactions in the digestive system [4]. However, not much is known about the effect of this drug on degenerative diseases. Therefore, the therapeutic effect of meloxicam combined with glucosamine sulfate on patients with osteoarthritis was investigated in the present study, and its effects on serum CTX-I, CTX-II, COMP and MMP-3 were determined.

\section{EXPERIMENTAL}

\section{Subjects}

Eighty-eight (88) osteoarthritis patients were assigned to control ( $n=44)$ and treatment groups $(n=44)$, using the random number table method. In the treatment group, there were 20 male patients and 24 female patients, aged 45 to 78 years old (mean age $=62.19 \pm 3.13$ years) . The course of disease in the treatment group was 5 to 17 years (mean course $=7.69 \pm 2.63$ years). The control group comprised 21 male patients and 23 female patients, with ages ranging from 43 to 75 years, and an average age of $60.27 \pm 2.97$ years. The course of disease in the control group was 5 to 17 years (mean course $=7.99 \pm 2.17$ years). There were no significant differences in age, sex and course of disease between the two groups $(p>0.05)$, as shown in Table 1 . This research received approval from the Ethical Committee of Ganzhou People's Hospital, No. 17 Hongqi Avenue, Ganzhou City, Jiangxi Province (approval no. 20188416), and was performed according to the Declaration of Helsinki promulgated in 1964, as amended in 1996 [5].

Table 1: Pre-treatment profile of patients $(n=44)$

\begin{tabular}{lcc}
\hline Group & $\begin{array}{c}\text { Treatment } \\
\text { group }\end{array}$ & $\begin{array}{c}\text { Control } \\
\text { group }\end{array}$ \\
\hline Sex (male/female) & $20 / 24$ & $21 / 23$ \\
Mean age (year) & $62.19 \pm 3.13$ & $60.27 \pm 2.97$ \\
$\begin{array}{l}\text { Course of disease } \\
\text { (year) }\end{array}$ & $7.69 \pm 2.63$ & $7.99 \pm 2.17$ \\
\hline
\end{tabular}

\section{Inclusion criteria}

The criteria for inclusion were consistent with the guidelines for diagnosis and treatment of osteoarthritis [4]. The following patients were included: patients who did not undergo any other treatment that might affect prognosis prior to admission; patients who had joint pain and swelling; patients with a clear mind and who were willing to cooperate with the taking the treatment regimen; and those who signed informed consent.

\section{Exclusion criteria}

Subjects with obvious abnormalities in liver, kidney and cardiac functions; patients allergic to the drugs used; patients with conditions that cause joint pain e.g. gout and pregnancy; and patients with mental sickness.

\section{Treatments}

The control group was treated with $7.5 \mathrm{mg}$ of meloxicam tablets (Shanghai Haling Biotechnology Co. Ltd, batch no. 20150118) twice a day. The treatment group was treated with glucosamine sulfate capsules (Shanxi Tongda Pharmaceutical Co., Ltd., batch number 20150107) $0.5 \mathrm{~g}$ (two pills, $0.25 \mathrm{~g}$ per pill), three times a day, in addition to meloxicam. The two groups were treated continuously for 8 weeks. During the treatment period, drugs such as glucocorticoids, as well as spicy and irritant foods and cold water bath were prohibited.

\section{Therapeutic parameters}

\section{Clinical effectiveness}

Lequesne index [6] was used to evaluate clinical symptoms, including joint pain when at rest, joint movement pain, tenderness, swelling, morning stiffness and walking ability. Different points (0 23) were allotted according to the severity of symptoms. Lequesne index was calculated from the sum of 6 items in the clinical symptoms, and the higher the score, the more serious the symptoms. The clinical effectiveness of the patients was evaluated after treatment. According to the degree of improvement in Lequesne index, and with reference to the criteria for evaluation of clinical effectiveness in the orthopedic department [7], the treatment effect were classified as cured (Lequesne index $\geq 80 \%$ ), remarkedly effective (Lequesne index $\geq$ $50 \%$ ), effective (Lequesne index $\geq 25 \%$ ), or ineffective (Lequesne index $<25 \%$ ). Visual analogue score (VAS) was used to evaluate the degree of pain, on a 10-point scale [8]. The 
higher the score, the more severe and intolerable the pain. Lysholm knee joint score [9] was used to evaluate motor function of the knee joint. It has 8 indices with scores ranging from 0 to 100, and the higher the score is, the better the motor function of knee joint.

\section{Biochemical assays}

Fasting venous blood ( $5 \mathrm{~mL}$ ) was taken in the morning and the levels of serum and joint fluid levels of CTX-I, CTX-II, COMP and MMP-3 were determined by enzyme linked immunosorbent assay (ELISA). Adverse reactions during the treatment were monitored in both groups.

\section{Statistical analysis}

The results are expressed as mean \pm SD. Comparison between the two groups was done with $t$-test. Numerical results are displayed $n(\%)$, and were compared using $x^{2}$ test. SPSS17.0 software package was used for all analyses. Values of $p<0.05$ were assumed to indicate statistical significance.

\section{RESULTS}

\section{Clinical effectiveness}

Table 2 shows that after treatment, the effectiveness in the treatment group (92.7\%) was higher than corresponding control value (75.0\%; $p<0.05)$.

\section{Therapeutic indices}

Before treatment, there were no significant differences in Lequesne index, Lysholm score and VAS score between the treatment and control patients $(p>0$. 05). However, post- treatment Lequesne index and VAS score of the two groups were lower than pre-treatment values, but were markedly less in patients in the treatment group $(p<0$. 05). On the other hand, Lysholm scores were increased in both groups after treatment, but the increase was higher in the treatment group. These results are shown in Table 3 .

\section{Serum parameters}

Table 4 shows that before treatment, serum levels of CTX-I, CTX-II, COMP and MMP-3 of both groups were comparable. After treatment, the serum CTX-I, CTX-II, COMP and MMP-3 levels in the two groups were markedly reduced $(p<0.05)$. However, post-treatment levels of these parameters were significantly lower control group values $(p<0.05)$.

\section{Adverse reactions}

The main adverse reactions during treatment were gastrointestinal reactions and pruritus. The adverse reactions did not last long. The affected patients recovered without treatment.

\section{DISCUSSION}

Knee osteoarthritis has the highest incidence among all the forms of osteoarthritis. It is caused by knee joint degenerative diseases. The early stage of osteoarthritis is characterized by pain, stiffness, hypertrophy and limited movement. In the late stage of osteoarthritis, the loss of joint function is due to cartilage peeling, necrosis, and hyper-osteogenesis. It is a consequence of phagocytizing of degradation products by synovial cells, leading to release of large amounts of IL-1 and TNF- $\alpha$ into the synovial fluid;

Table 2: Clinical effectiveness of treatments ( $n, \%)$

\begin{tabular}{lccccc}
\hline Group & Cured & $\begin{array}{c}\text { Remarkably } \\
\text { effective }\end{array}$ & Effective & Ineffective & $\begin{array}{c}\text { Total } \\
\text { effectiveness }\end{array}$ \\
\hline Control & $18(40.00)$ & $8(17.18)$ & $7(17.55)$ & $12(26.67)$ & $33(75.00)$ \\
Treatment & $34(53.33)$ & $9(20.00)$ & $8(17.78)$ & $4(8.89)$ & $55(92.73)$ \\
$X^{2}$ & & & & & 2.581 \\
$P$-value & & & & & 0.015 \\
\hline
\end{tabular}

Table 3: Therapeutic indices before and after treatment (mean \pm SD, $n=44$ )

\begin{tabular}{lcccc}
\hline \multirow{2}{*}{ Index } & \multicolumn{2}{c}{ Control group } & \multicolumn{2}{c}{ Treatment group } \\
\cline { 2 - 5 } & Before treatment & $\begin{array}{c}\text { After } \\
\text { treatment }\end{array}$ & $\begin{array}{c}\text { Before } \\
\text { treatment }\end{array}$ & $\begin{array}{c}\text { After } \\
\text { treatment }\end{array}$ \\
\hline Lequesne index & $13.68 \pm 4.16$ & $7.24 \pm 3.42$ & $12.34 \pm 4.67$ & $4.78 \pm 3.34^{* \#}$ \\
Lysholm score & $47.63 \pm 10.34$ & $71.46 \pm 12.58^{*}$ & $50.07 \pm 10.15$ & $83.82 \pm 11.01^{* \#}$ \\
VAS score & $7.24 \pm 1.25$ & $3.66 \pm 1.07$ & $7.09 \pm 1.16$ & $2.35 \pm 1.08^{* \#}$ \\
\hline${ }^{*} P>0.05$, relative to pre-treatment, \#p>0.05, relative to control & &
\end{tabular}


Table 4: Serum CTX-I, CTX-II, COMP and MMP-3 (mean \pm SD, $n=44)$ )

\begin{tabular}{lccccc}
\hline \multirow{2}{*}{ Group } & \multicolumn{2}{c}{ Control group } & & \multicolumn{2}{c}{ Treatment group } \\
\cline { 2 - 3 } \cline { 5 - 6 } & Before treatment & After treatment & & Before treatment & After treatment \\
\hline CTX-I $(\mathrm{ng} / \mathrm{mL})$ & $256.83 \pm 98.89$ & $137.29 \pm 194.66$ & & $245.29 \pm 98.76$ & $125.68 \pm 152.76^{\# \#}$ \\
CTX-II $(\mathrm{ng} / \mathrm{mL})$ & $232.14 \pm 215.06$ & $209.591 \pm 95.65$ & & $201.08 \pm 192.46$ & $192.681 \pm 85.43^{* \#}$ \\
COMP $(\mu \mathrm{g} / \mathrm{mL})$ & $1.83 \pm 1.98$ & $1.351 \pm 25$ & & $1.76 \pm 1.54$ & $1.15 \pm 1.18^{*}$ \\
MMP-3 $(\mathrm{ng} / \mathrm{L})$ & $30.56 \pm 6.68$ & $22.20 \pm 5.26$ & & $32.02 \pm 6.80$ & $17.88 \pm 5.20^{* \#}$ \\
\hline${ }^{*} P>0.05$, relative to pre-treatment; $\# p>0.05$, relative to control group
\end{tabular}

these affect the metabolism of chondrocytes and aggravate the development of the disease $[10,11]$. Due to large trauma and high cost of surgical treatment, non-steroidal antiinflammatory drugs and cartilage protectants are often used to treat patients with knee osteoarthritis.

It has been shown that meloxicam and glucosamine sulfate can relieve pain and swelling in knee osteoarthritis patients through significant control effect on advanced cartilage necrosis [9]. In this study, meloxicam combined with glucosamine sulfate was used to treat osteoarthritis patients and good clinical results were achieved. Meloxicam is a new non-steroidal analgesic and anti-inflammatory drug which inhibits prostaglandin biosynthesis by blocking COX-2. Thus, it has anti-inflammatory and analgesic effects, and is the preferred drug for osteoarthroid diseases [12]. It was found that the adverse reactions of meloxicam were reduced, the tolerance was better, and it was easily accepted by the patients.

Glucosamine sulfate slows down bone degradation and promotes the regeneration of cartilage. It inhibits the enzymes collagenase and phospholipase A2 which damage cartilage, and prevents the production of superoxide free radicals in injured cells [13]. Therefore, it was hypothesized that the combination of meloxicam and glucosamine sulfate could enhance antioxidative stress activity and reduce damage to chondrocytes. The results obtained showed that the effectiveness in the treatment group was 92.7 $\%$, while the effectiveness in the control group was $75.0 \%$. This is consistent with previous findings [9].

There are many reports on the treatment of osteoarthritis using meloxicam combined with glucosamine sulfate, but studies on CTX-I, CTXII, COMP, and MMP-3 are limited. It is known that CTX-I is the most abundant form of collagen in humans, and is the only collagen in bone. It can be released into blood and partly into urine when absorbed by bone. It is derived from mature type I collagen which cannot be degraded in human body, and it directly reflects the degradation of collagen fibers. Thus, CTX-II is one of the effective indicators of the degree of osteoarthritis, and it is very sensitive to drug therapy.

The strongest area of COMP immune-labeling is the added-value zone matrix and growth plate of immature articular cartilage, which is an important non-collagen component of cartilage. In a study, 115 patients with osteoarthritis were followed up for 5 years and it was found that COMP in patients with middle- and late-stage osteoarthritis was markedly higher than in patients at the initial stage. This indicates that the degree of joint injury in patients with osteoarthritis was positively correlated with the level of serum COMP [14]. Therefore, more and more attention has been paid to COMP as a marker of articular cartilage injury.

Matrix metalloproteinase-3 (MMP-3), a protease that degrades extracellular matrix, is present in normal humans. It is involved in the degradation of cartilage matrix and bone resorption, and is highly expressed in osteoarthritis patients. In this study, the serum CTX-I, CTX-II COMP and MMP-3 levels were significantly lower after treatment than those before treatment. After treatment, joint pain, swelling and joint stiffness were reduced to a great extent. The results further indicate that glucosamine sulfate is beneficial in reducing serum CTX-I, CTX-II, COMP and MMP- 3 levels and promoting the regeneration of cartilage.

\section{Limitations of the study}

Due to the small sample size, short follow-up time and possible errors in the study, further research is needed to confirm its long-term effectiveness.

\section{CONCLUSION}

Meloxicam combined with glucosamine sulfate is effective in the treatment of osteoarthritis. It effectively reduces serum CTX-I, CTX-II, COMP and MMP-3 concentrations, and also relieves clinical symptoms such as joint pain, swelling and joint stiffness in patients with osteoarthritis. Moreover, it is not associated with any serious adverse reaction, indicating that the regimen is 
beneficial in the treatment of osteoarthritis patients.

\section{DECLARATIONS}

\section{Conflict of interest}

No conflict of interest is associated with this work.

\section{Contribution of authors}

We declare that this work was done by the author(s) named in this article and all liabilities pertaining to claims relating to the content of this article will be borne by the authors. All authors read and approved the manuscript for publication. Lu Zhijun conceived and designed the study, Lu Zhijun, Chen Rongchun, Lin Feixiang, Wu Yaohong, Liu Ning, Zhang Shufang, Zhong Mingliang, Zhong Hongfa collected and analysed the data, while Zhong Hongfa wrote the manuscript.

\section{Open Access}

This is an Open Access article that uses a funding model which does not charge readers or their institutions for access and distributed under the terms of the Creative Commons Attribution License (http://creativecommons.org/licenses/by/ 4.0) and the Budapest Open Access Initiative (http://www.budapestopenaccessinitiative.org/rea d), which permit unrestricted use, distribution, and reproduction in any medium, provided the original work is properly credited.

\section{REFERENCES}

1. Chen $Y$, Chen $Y$, Yan $H$, Wang $X$. Analysis of light incident location and detector position in early diagnosis of knee osteoarthritis by Monte Carlo simulation. Proceedings Spie 2017; 245: 1024505.

2. Zhang SC, Du XH. Clinical effect analysis of diacerein, glucosamine sulfate combined with sodium hyaluronate in the treatment of knee osteoarthritis. Chinese Primary Health Care 2018; 3: 90-91.
3. Yin WF, Chen S, Li WK, Li XY, Guo FJ, Zhang WK. Clinical research of glucosamine sulfate combined with etoricoxib for the treatment of knee osteoarthritis. Orthop 2016; 7(3): 190-194.

4. Li PP, Tai Y, Huang CB, Zhang LL. Clinical trial of meloxicam combined with methotrexat in the treatment of rheumatoid arthritis. Chin J Clin Pharmacol 2016; 32(22): 2023-2026.

5. World Health Organization. Declaration of Helsinki. Br Med J 1996; 313(7070): 1448-1449.

6. Martin LM, Massafra U, Bizzi E, Migliore A. A double blind randomized active-controlled clinical trial on the intra-articular use of Md-Knee versus sodium hyaluronate in patients with knee osteoarthritis ("Joint"). BMC Musculoskelet Disord 2016; 17(1): 94.

7. Xiong $F L$, Xiao GC, Li XP, Yang $H$, Chen YL, Chai $L$. Efficacy on Knee Osteoarthritis Treated with HydroAcupuncture of Mi-ao Medicines. World J Integr Tradit West Med 2014; (3): 266-268

8. Han HD, Jiang JZ, Zhang HL, Sang L, Han GB. Clinical trial of meloxicam combined with glucosamine sulfate in the treatment of patients with osteoarthritis. Chin J Clin Pharmacol 2018; (10): 1151-1154.

9. Huang LC, Hu HM, Liang YX. Review of Knee Function Evaluation Form. China Med Pharm 2016; 6(13): 50-53.

10. Marini S, Fasciglione GF, Monteleone G, Maiotti M, Tarantino $U$, Coletta M. A correlation between knee cartilage degradation observed by arthroscopy and synovial proteinases activities. Clin Biochem 2003; 36(4): 295-304.

11. Bluteau G, Gouttenoire J, Conrozier T, Mathieu P, Vignon $E$, Richard M, Herbage D, Mallein-Gerin F. Differential gene expression analysis in a rabbit model of osteoarthritis induced by anterior cruciate ligament (ACL) section. Biorheology 2002; 39(1-2): 247-258

12. Yin WF, Chen S, Li WK, Li XY, Guo FJ, Zhang WK. Clinical research of glucosamine sulfate combined with etoricoxib for the treatment of knee osteoarthritis. Orthop 2016; 7(3): 190-194.

13. Momomura $R$, Naito $K$, Igarashi $M$, Watari $T$, Terakado $A$, Oike S, Sakamoto K, Nagaoka I, Kaneko K. Evaluation of the effect of glucosamine administration on biomarkers of cartilage and bone metabolism in bicycle racers. Mol Med Rep 2013; 7(3): 742-746.

14. Cao H, Zou HB, Zhang L, Zhang J. Clinical observation of Duhuo Jisheng decoction in treatment of knee osteoarthritis with deficiency of liver and kidney. China Med 2017; 12(3): 392-395. 